\title{
(Anvironmental Management Challenges of aße Emerging Industrial Firms: Evidence from Research House Addis Ababa City, Ethiopia
}

\author{
Samuel Urkato ${ }^{*}$, Hio-Jung Shin ${ }^{2}$ \\ ${ }^{1}$ Centre for Environment and Development Studies, College of Development Studies, Addis Ababa University, ETHIOPIA \\ ${ }^{2}$ Agricultural and Resource Economics, Kangwon National University, and Korea Association of Rural Tourism, SOUTH KOREA \\ *E-mail for correspondence: samatouk@gmail.com \\ Received: Jun 30, 2015; \\ Accepted: Jul 14, 2015; \\ Published: Aug 06, 2015 \\ Source of Support: Nil \\ No Conflict of Interest: Declared
}

\begin{abstract}
In developing economies like Ethiopia, emerging industries are mostly subject to state protection, as a prominent rationale articulated by Hamilton (1791). However, they are less responsive to environmental health degradation caused by their effluent. In this paper, Akaki River pollution in Addis Ababa city is thought-out to understand how those industries aligning the river bank are polluting the environment and how local policy is responding to regulate it. By using secondary information, focus group discussion and key informant interview, this study describes that Ethiopian environmental policy, which addresses state and market approaches, is silent to protect the pollution. However, the societies in the catchment areas, whom lack proper property right of the river, are seriously vulnerable to family health since they use the polluted river water for smallholder farming, drinking, and other domestic activities. Moreover, the weak performance of this policy is a burden for other sectoral policies such as health and agriculture. Empirical studies for river pollution impact are further needed.
\end{abstract}

Keywords: Emerging industry, environmental resource, policy, Addis Ababa

\section{INTRODUCTION}

As economic reasoning articulated by Hamilton (1791) and his followers concerned, nascent industries often do not have the economies of scale that their older competitors from other countries may have, and thus need to be protected until they can attain similar economies of scale. Indeed, this theory suffers from empirical imprecision and is further challenged by promoters of infant economy protection (Rosenstein-Rodan, 1963; Scitovsky, 1954; Baldwin, 1965; Grubel, 1966). However, in a few transition economies, a state perception to protect emerging local industries from international competition concealed local impacts of those industries. Yet, local impacts of those "infant industries" on human environment are meaningful and on the lookout for innovative tools and policy approaches.

In this descriptive article, Ethiopia and hence Addis Ababa City is taken as one of a few rapidly growing as well as emerging economies in the contemporary African economic record so as to understand the trend of infant industries' concern to environmental resource management and the rule-of-games thereof. Past studies relating to industry and environmental management with specific focus on river pollution in Addis Ababa, the capital city of Ethiopia, are reviewed in this article. A few descriptive as well as experimental and merely disciplinary studies available (Zawide and Komolrit, 1974; Zawide 1976; Yesehak and
Sinkenesh, 1994; Itanna, 1998; Fisseha, 1998; Adane, 1999; Mebratu, 1999 and 2000; Mohamad, 2002; Teklehaimanot, 2003; Chekole, 2006; Mersha, 2008) and selected institutional reports to date (EDVSA and Halcrow, 1989; UAO, 2002; CGASBPDA, 2003; EPA Ethiopia, 1999; CRGE, 2011) related to Akaki River Basin in Addis Ababa City are reviewed.

One agreed up on debate in common for all these evidences reviewed is that the discharge of untreated effluent, solid wastes and wastewater from industries, households and institutions are the main sources of the river pollution and the pollution status is also risky to environment, human life and lives in the river. More than 2,000 registered industries in the city (more than $70 \%$ of all industries in the country) are located along the river banks and $90 \%$ of all industries lack facilities for some degree of onsite treatment plant, and subsequently discharge effluents into adjacent streams (EPA, 2007). These industries mostly seem to be waived from payments for environmental services (PES); if not unobservable. Moreover, their period of transition to maturity for significant level of local and international trade competition as well as "infant industry" protection instruments arranged for these industries in the country are not well known, but their local impacts on river pollutions, human health, and smallholder irrigation in the basin are becoming worse through time. However, 
empirical policy analysis regarding industry competitiveness and state protection arrangements as well as assessment on their activities' impact on welfare of society is not the scope of this study. And the focus here is to understand the current status of environmental management practice in the city from theoretical point of view, past evidences and based on descriptive information from the public perception in the area.

\section{LITERATURE REVIEW}

\section{Infant-industry argument versus infant economy protection}

The classical infant-industry argument (see List, 1856, Hamilton, 1791, Bastable and Mill, 1909) for protection has long been regarded by economists as the major "theoretically valid" exception to the case for worldwide free trade. Debates against the hypothesis mostly argue (Rosenstein-Rodan, 1963; Scitovsky, 1954; Baldwin, 1965; Grubel, 1966) that not only do infant-industry duties distort consumption-as do all duties-but they may fail to achieve a socially efficient allocation of productive resources in new industries and may even result in a decrease in social welfare. Recently, debates against infant industry arguments move forward to infant economy protection (Rosenstein-Rodan, 1963; Scitovsky, 1954; Baldwin, 1965; Grubel, 1966).

In Meade (1955: 256) it is noted that the existence during early stages of production experience of higher costs than those of foreign competitors is, by itself, insufficient justification for tariff protection on grounds of economic efficiency. In Baldwin (2013) it is indicated that infantindustry tariff reduces welfare by being ineffective in shifting a country's production possibility curve outward, yet causing a consumption loss due to the rise in the price of the imported good above its world level. Though, protection from international competition is one of inefficiency indicators of domestic industries, it has gained much importance in merging democratic developmental state regime (Johnson, 1982) and nations.

However, empirically testing the validity of both arguments is beyond the scope of this study. Moreover, this study is not denying the importance of selective protection that allows socially efficient allocation of resources. But, new industries in merging economies fail to achieve a socially efficient allocation of productive resources and may even result in a decrease in social welfare in areas such as environmental pollutions in cities.

Economies in transition, in particular, have been rapidly industrializing; nevertheless, their emerging industries while it has had positive effects on economic growth; it has also caused pollution with severe effects on the natural environment, human health, and global climate change (Rooij, 2008). This has also affected the implementation of other sectoral policies within a country. Rooij further indicated that pollution regulation efforts in lately industrializing countries are more difficult because of the characteristics of local enterprises and their management. Their enterprises are many but smaller, functioning with minimal profit margins, unable to invest in and operate pollution abatement equipment, informal, older state-owned with outdated equipment and profit-ability options, a low level of legal and environmental awareness among management and have dominant local employers in the newly industrializing transition context, who are able to use their power to receive beneficial treatment from regulators and local communities. Due to these firm and industry manners, protectionist approach is exceptionally rewarding for political economy of the emerging economies.

However, socially optimal protection instruments for a developmental state, which is striving to meet rapid economic growth, poverty reduction, and environmental degradation is a challenge for countries like Ethiopia. For instance, experiences and past evidences indicated that environmental policy instruments remain silent to regulate the environmental pollutions severely affecting social welfare in Ethiopia. Hence, selective protection and rising environmental knowledge of the emerging industries through developmental alliance (Johnson, 1982) and jointly investing on alternative progressive interventions such as industrial innovation alliance can be argued, not against, to reconcile infant industry protection approaches in newly emerging developmental states like Ethiopia.

\section{Context of environmental policy in Ethiopia}

Keeley and Scoones (2003) discussed a range of debates that have emerged in Ethiopia over the last three decades. They summarized debates surrounding three core questions regularly posed by policy analysts. Firstly, what can be done to increase food production in a country prone to substantial food deficits and with a rapidly increasing population? Secondly, what can be done to ameliorate the progressive degradation of natural resources? And thirdly, what can be done to promote effective participatory management of natural resources by rural communities? Linked to these questions, three broad policy discourses identified in their assessment are the Green Revolution, an environmental rehabilitation, and an emergent participatory naturalresource management since the year 1960s. These authors believe that mostly perceptions of crisis, in particular, have informed and shaped environmental policy-making in Africa, like; the issues of soil fertility decline, deforestation and desertification, which are deeply entrenched as problems for policy concern. The same study perceives that most policy making process of African countries in particular are influenced by some perspectives and interests from international environments and neglect the local context. However, in the contemporary policy world the intersection of national and international policy processes is, as they argue, particularly important.

The discourse-driven environmental policy of Ethiopia (EPA, 1997) is recently coupled with Climate Resilient Green Economic Development Path (CRGE, 2010), a strategic paper adopted to implement climate adaptation and mitigation programmes and projects. The overall policy goal is to improve and enhance the health and quality of life of all Ethiopians and to promote sustainable 
social and economic development through the sound management and use of natural, human-made and cultural resources and the environment as a whole so as to meet the needs of the present generation without compromising the ability of future generations to meet their own needs.

In this paper, however, the intent is to understand the policy instruments adopted for environmental protection that safeguard social welfare cracked by loosely managed infant industries in Addis Ababa and other parts of the country. Even though there is no specific orientation by infant industry hypothesis for stage of development path for infant industries, state should take regulatory actions to protect human welfare suffering from industrial wastes and pollutions. In the key guiding principles of Environmental Policy of Ethiopia (1997), market-based mechanisms and command-and-control type of regulations are adopted to implement for environment protection in the country. However, this highly celebrated policy document for mixed approaches is still less practiced at grass-roots level.

Studies evidenced that the pattern and nature of policy implementation is the major explanation for the failure or success of any given policy. In this vein, Nwankwo and Apeh (2008) observe that the implementation of a policy is the most vital phase in the policy process as it is at this stage that the success or failure of a policy is determined. Ikelegbe (2006) and Nweke (2006) in this respect too, note that many policy failures result from ineffective implementation. In order words, the hallmark of any successful policy is effective implementation as it is only effectively implemented policy that solves societal problems. For this too, Dick (2003) argues that policy implantation is about the most critical dimension in the policy process given the fact that the success or failure of any given policy is, to a high degree, a function of implementation. Responsive environmental policy, inclusive of other policies, to social problems is not only a matter of policy formulation, but also it depends on policy making process and its effective implementation. This paper argues that environmental policy of Ethiopia is subject to implement both commonand-control and market based instruments to manage environmental challenges, but it is ineffective to protect environmental degradation in practice. However, the factors hindering its implementation are still vague and demand further comprehensive policy impact analysis, which is not part of this paper.

Akaki River vulnerability to environmental degradation Descriptive as well as experimental studies (Zawide and Komolrit, 1974; Zawide 1976; Yesehak and Sinkenesh, 1994; Itanna, 1998; Fisseha, 1998; Adane, 1999; Mebratu, 1999 and 2000; Teklehaimanot, 2003; Samuel, 2005; Chekole, 2006; Mersha, 2008; Gebre and Rooijen, 2009 and others) and institutional reports to date (EDVSA and Halcrow, 1989; UAO, 2002; CGASBPDA, 2003; EPA Ethiopia, 1999) concerned with Akaki River Basin in Addis Ababa City are increasing through time. However, their effect on policy making or implementation remained silent. Moreover, almost all are highly basic researches and inclined to a specific discipline. However, environmental degradation is becoming a multidisciplinary approach, which can better influence development policy implementation. In general, these studies have similarities in findings. All enlighten that Akaki River is polluted due to discharges of untreated effluent from industries, surface run-off, human excreta, solid wastes and wastewater from households and institutions. By using groundwater model, for instance, Leta (2010) revealed that the flow lines intersect with the Akaki River in numerous places. The flow lines converge towards Akaki well field, implying contaminated water from the upper part of the aquifer will be pulled into the wells. Therefore, there is a high risk of vulnerability of the well field to pollution. Others are also concerned with identifying specific pollutant substances of the river.

These studies also agree that the major pollutant industries in the area are tanneries, breweries, wineries, distilleries, battery factories and, a slaughter house. As per their report, industrial effluents are discharged either directly into the river and its tributaries or after partial treatment. As a result of this pollution, it would be difficult to see aquatic life such as fish in the river (Leta, 2010). Despite its bad odor, black color and toxicity, the Tinishu Akaki River is still used for various purposes including laundry, bathing, swimming, irrigation and cattle drinking (Samuel, 2005). One important challenge of these studies is their sole concern on sources of problems, but investigations that devise solutions in terms of innovative tools and approaches to combat such environmental damages are scant in the area.

Studies related to wastewater use effect on irrigated land and hence human health is also physically diverse (Singh et al., 2003; Sharmaa et al., 2007; Liu et al., 2005; Lia et al., 2009). Regardless of their geographic difference, all concur that heavy metals from industrial areas have significant effect on soil pollution and its production. Thus, human health is affected due to a consumption of farm products using wastewater for irrigation, domestic uses, and drinking without any treatment.

Therefore, emerging water scarcity crisis due to climate change and environmental degradation will result in conflicts among users and polluters arising from river basins in domestic economy or from riparian countries using trans-boundary river. Thus, Akaki River shares this scenario because it contributes to stallholder irrigation for the lower basin rural and semi-urban households and a tributary for Awash River, which serves hydropower generation and large scale irrigation projects in the country. It is an early warning that emerging industrialization of the country would further affect the vulnerable river and its users. Through stronger partnership, institutions, business organizations, urban households, the lower basin users, civil society organizations and other stakeholders can device an innovative tools and approaches to reverse the common pool resource hazard of Akaki River type. 


\section{Materials AND Methods}

\section{Description of study area}

The site of Addis Ababa City was chosen by Empress Taytu Betul and it was founded in 1886 by her husband, Emperor Menelik II. Currently, Addis Ababa city is attracting international communities for market, tourism, seminars, conferences and delegation. The city has ten sub-city administrations namely: Kirkos, Gullele, Kolfe Keranio, Akaki Kaliti, Nifas Silk-Lafto, Lideta, Bole, Addis Ketema, Yeka, and Arada. Akaki River Basin crosses at least five sub-city administrations borders, which calls for integrated natural resource management approach in the city. Addis Ababa has a subtropical highland climate. The city has a complex mix of highland climate zones, with temperature differences of up to $10^{\circ} \mathrm{C}$, depending on elevation and prevailing wind patterns. The high elevation moderates temperatures year-round, and the city's position near the equator means that temperatures are very constant from month to month. Based on the 2007 Census conducted by the Central Statistical Agency of Ethiopia (CSA), Addis Ababa has a total population of $2,739,551$, of whom $1,305,387$ are men and 1,434,164 women; all of the populations are urban inhabitants. For the capital city 662,728 households were counted living in 628,984 housing units, which results in an average of 4.1 persons to a household. Although all Ethiopian ethnic groups are represented in Addis Ababa due to its position as capital of the country, the largest groups include the Amhara $(47.04 \% \%)$, Oromo (19.51\%), Gurage (16.34\%), Tigray $(6.18 \%)$, Silt'e (2.94\%), and Gamo (1.68\%). Languages spoken include Amharic (71.0\%), Oromiffa (10.7\%), Gurage (8.37\%), Tigrinya $(3.60 \%)$, Silt'e $(1.82 \%)$ and Gamo $(1.03 \%)$. The religion with the most believers in Addis Ababa is Ethiopian Orthodox with
$74.7 \%$ of the population, while $16.2 \%$ are Muslim, $7.77 \%$ Protestant, and $0.48 \%$ Catholic.

\section{Data and methods}

This study uses secondary data from World Resource Institute database (WRI, 2013) and primary data collected from focus group discussion and key informant interviews. The World Resource Institute database also provides information on other socioeconomic variables for longer time period. For this study, Nitrous Oxide emissions (1990-2010), Water pollution by industry type (1990-2007), Energy production and use pattern (1971-2010), CO2 per capita and GDP per capita (19802010) are extracted to understand the trend of environmental quality through time in the city. Descriptions are demonstrated by tables, figures and graphs that indicate trend of environmental pollutants in the city. Focus group discussion is formed from households using micro-irrigation and slum area dwellers in the city, in addition to key informant interview of stakeholders from three sub-city administrations, water and sewerage management office, environment and resource management offices, health centres and offices, small and medium scale business offices and tourism offices. Qualitative information is present in text discussion. Secondary information from World Resource Institute database, focus group discussion and key informant interview are critically analyzed to understand the trend and current status of city environmental degradation, the level of public awareness about environmental policy in the city, and effect of city river pollution and sources of its pollution. Evidences in the past studies in the area are reviewed through the process of this study in order to bring together the knowledge. Gaps of study up to date that call for future endeavors are also identified in this piece.

Table 1: Nitrous Oxide emissions (1990-2010) in Ethiopia (90\% of the industries base in Addis Ababa City)

\begin{tabular}{|c|c|c|c|c|c|}
\hline Nitrous Oxide emission & 1990 & 2000 & 2005 & 2008 & 2010 \\
\hline Nitrous oxide emissions (thousand metric tons of $\mathrm{CO}_{2}$ equivalent) & 25278.6 & 26660.5 & 30267.2 & 36844.3 & 39072.1 \\
\hline $\begin{array}{l}\text { Nitrous oxide emissions in energy sector (thousand metric } \\
\text { tons of } \mathrm{CO}_{2} \text { equivalent) }\end{array}$ & 659.1 & 1450.5 & 1594.3 & 1718.7 & 1816.7 \\
\hline $\begin{array}{l}\text { Nitrous oxide emissions in industrial and energy processes } \\
\text { (\% of total nitrous oxide emissions) }\end{array}$ & 2.607344 & 5.440633 & 5.267418 & 4.664765 & 4.649609 \\
\hline
\end{tabular}

Source: Own calculation from world resource institute database (2013).

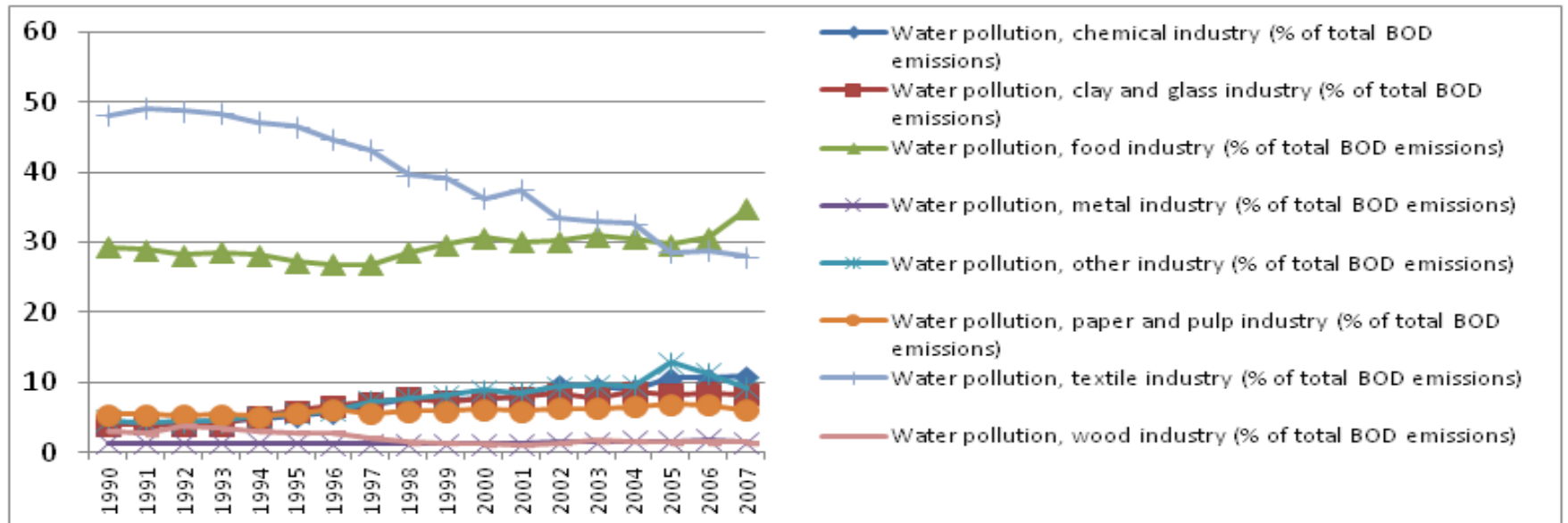

Figure 1: Water pollution by industry type (1990-2007). Source: own calculation from World Resource Institute database (2013) 


\section{Descriptive analysis of environmental quality the city}

In Ethiopia, almost $90 \%$ of the country's medium and large scale industries are established in Addis Ababa city along with Akaki river basin (Africa Enterprise Survey, 2011; Ethiopian Science and Technology Mister, 2008). Rough evidence based on World Resource Institute database on the trend of pollutant gas emission in the city for a decade indicated (Table 1) that its volume is increasing through time. However, studies in the area disclosed that most of those industries have lack of pollution treatment technologies; therefore, they discharge harmful chemicals and industrial wastes to the residing Akaki river catchments. Table 1 shows trends of harmful chemical discharges to the environment. For the periods (1990-2007) data present, almost all industries except textile and wood industries have increasing trend of pollution effect on water as measured in terms of a percent of total BOD (Biochemical Oxygen Demand) emissions (Table 1). Indeed, more than 2,000 registered light, medium and large scale industries in the city are less regulated by local or national policy instruments for environmental pollutions. As indicated in Figure 1 shows that all major industries have shown their pattern of discharging pollution to the river in the area. This rough information gives a clue that industries in the city have either:

- Lack of technology, which is costly, to treat the pollutants,

- $\quad$ Lack of regulatory enforcement to manage pollutions and remain negligent,

- Lack of environmental awareness or

- A combination of these options.

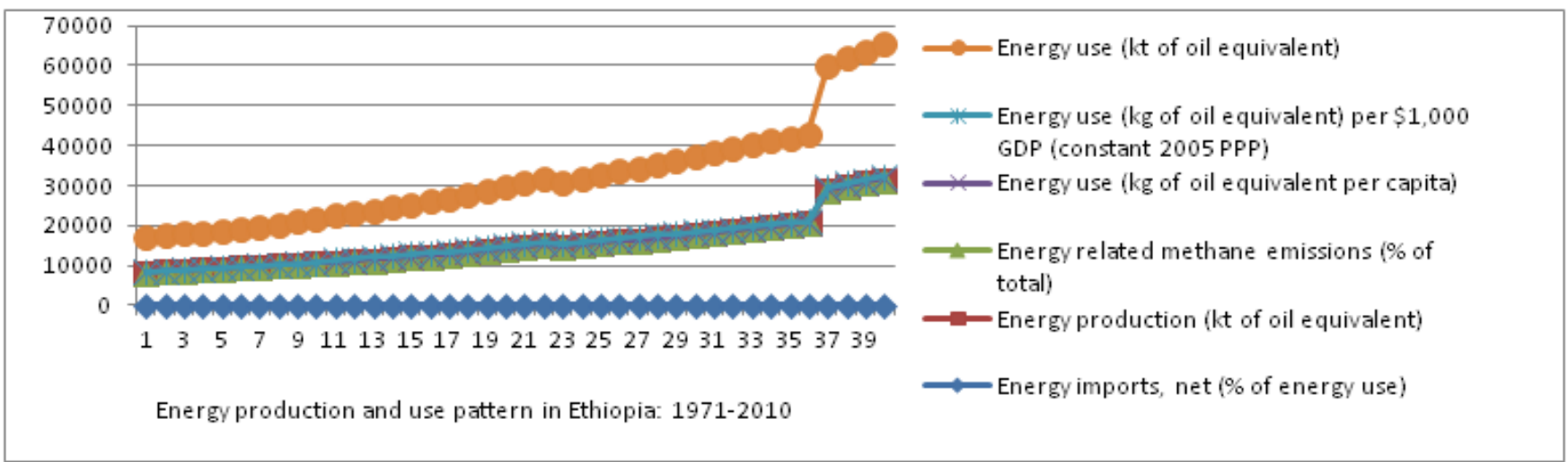

Figure 2: Energy production and use pattern in Ethiopia: (1971-2010). Source: own calculation from World Resource Institute database (2013)
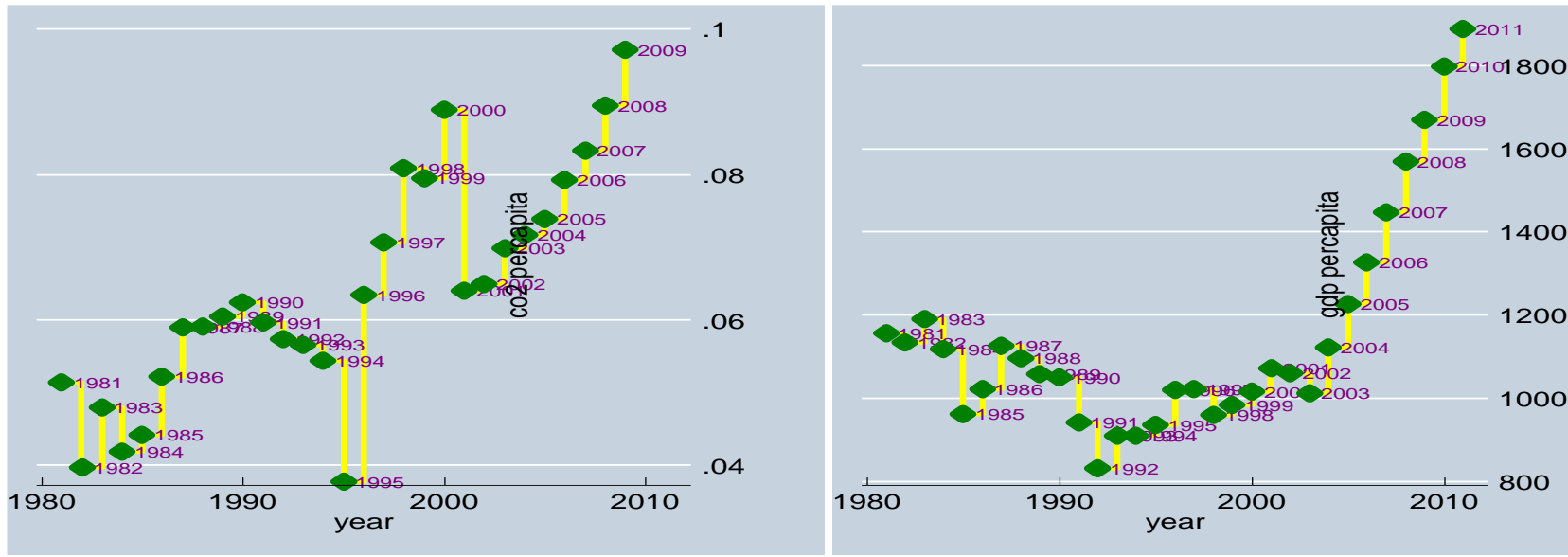

Figure 3: $\mathrm{CO}_{2}$ per capita and GDP per capita relationship for the year 1980-2010 in Ethiopia. Source: Own computation form World Resource Institute data (2012)

Moreover, there is asymmetry of information in their release of pollutants to the river basin. Furthermore, the city in particular uses energy inefficient vehicles and emits pollutants to environment. The vehicle garages and car washing services have low technologies and discharge all contaminated water and chemicals to ditches in the city. Rain washes all those chemicals and waste water to the river bank in the city. This type of pollution practice is the worst case in other parts of cities in the country. Figure 2 demonstrates the trend of energy production and use pattern in the specified period in the country and major part resides in the capital city of Ethiopia, Addis Ababa.

It is still illustrative that Green House Gas (GHG) emissions $\left(\mathrm{CO}_{2}\right.$ emission in metric tons per capita) volume to some extent mimics the trend of GDP per capita, which is rising up continuously for the specified period. 
Figure 3 indicates environmental quality indictor (GHG$\mathrm{CO}_{2}$ ) and per capita GDP growth for the specified period in the country. Larger part of GHG emission is released from Addis Ababa city industrial activities. Increasing liquid fuel energy consumption, newly emerging industrial and manufacturing sectors, inefficiently consuming obsolete transportation means, emerging urbanizations and related construction industries are a few of sources contributing to $\mathrm{CO}_{2}$ emissions. It is also consistent with the assumption of the theory (Kuznet, 1955) dictating that pollution intensity rises with per capita income at the early stages of economic development, in which these countries are, and falls as per capita income rises beyond some threshold level that could be determined.

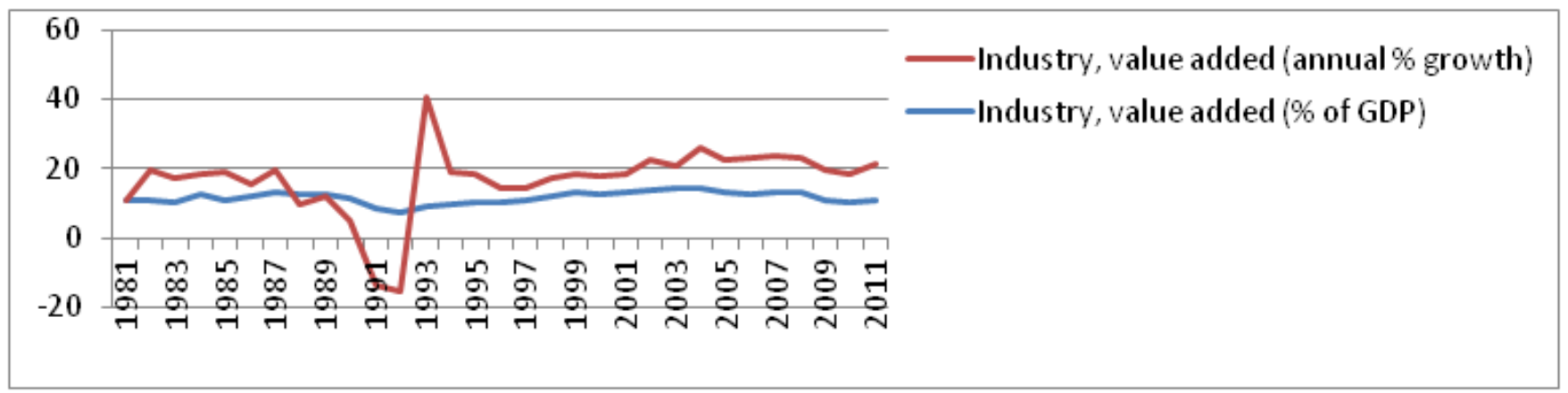

Figure 4: Industrial sector growth trend (1981-2011). Source: Own computation form World Resource Institute data

Industrial Growth trend in Ethiopia has been very stagnant for the last three decades (Figure 4). The two national development plans "The Sustainable Development and Poverty Reduction Program (SDPRP) 2002/2003-2004/2005" and "A Plan for Accelerated and Sustained Development to End Poverty (PASDEP) 2005/2006-2009/2010" prioritized agriculture as an engine of growth. In this planning regimes, the government had little practical knowledge or experience of industrial policy and had to start with a simple strategy of giving generous incentives and disproportionate policy attention to a few selected export-oriented sectors including leather and leather products, textile and garment, and agro products (floriculture was later added as the private sector discovered its potential). However, the newly formulated plan, Growth and Transformation Plan (2010/2011-2014/2015), is intended to the promotion of import-substituting industries in addition to exportoriented ones, institutionalization of kaizen as a productivity tool in addition to benchmarking, proposed enhancement of micro and small enterprise (MSE) policy, expansion of the TVET system, creation of new industrial zones, and general speeding up of industrialization. However, the industrial growth trend is fragile and their production costs are not socially optima. Thus, as the growing industries, their transaction costs as well as environmental pollution abatement costs are less considered in their cost estimation. However, their pollutant discharges are severely affecting human health in the river catchments. Figure 4 demonstrates Ethiopian industrial growth trends for the last a few decades (19822011).

\section{Environmental degradation watch-dog views}

Even though, the public is not well aware of its power, they have regulatory position in the country in democratic developmental regimes and this paper prefers to use watch-dog to represent the respondent in this study from key informant interview and focus group discussion. In this sub-section, information from focus group discussion and key informant interview is critically analyzed to understand the trend and current status of the city environmental degradation, the level of public awareness about environmental policy in the city, and effect of city river pollution and sources of its pollution. Households using micro-irrigation and slum area dwellers in the city have no clear information about environmental enforcement regulations of the city, but they know the severe effects of Akaki river pollution on human health and their small scale farming. They produce their farm products for their household or individual livelihood needs. Key informant interview conducted to officials and stakeholders in the sub-cities confirmed that they have no clear policy instrument knowledge to stop river pollution, except the greening and cleaning propaganda of the top-down approaches. They further agree that there is no project or program commitment from the public sector, the industries or civic organizations to manage ever affected river pollution in the city. They all agree that waste management approach of the city is so poor.

This rough information from key informant interviews and focus group discussants, besides past study reviews, rise further questions for future investigations in the city. Future investigations focusing on household welfare effects due to river pollution; effectiveness of existing policy tools and approaches; emerging industries' production plan and their level of innovation to upgrade technologies and entrepreneurial approaches to optimize firm and industry performance; job creation potential of the river basin through recreations, urban agri-business, besides its climate mitigation potential are all missing during the course of literature review for this study. The studies with interdisciplinary or trans-disciplinary 
approaches can improve the past literatures inclined to a specific discipline. However, the environmental degradation is becoming a cross-cutting development agenda and demanding a solution from diverse disciplines.

\section{CONCLUSION}

Protection of a growing industry from international competitions for a shorter time span was exceptionally accepted even in a world with free market economy. Arguments against infant industry protection; however, inclined to infant economy protection due to diverse challenges of the former argument. Their debate has left a lesson for emerging democratic developmental states to strive for protecting their industries and the economy as a whole. However, the link between emerging industry growth and environmental management lacks integration and upsetting social welfare when rivers are polluted by industrial hazards with inefficient resource allocation scheme. Descriptive and experimental studies in the past using Addis Ababa city as a case identified that industrial discharges to Akaki River Basin are harmful for human health, the environment and water bodies in the catchment. However, Ethiopian Environmental Policy document, which addresses to employ both command-and-control and Market Based Instruments (MBIs), remained silent to regulate and relocate the resource degradation in the city in particular and in the country at large.

Results from World Resource Institute database, focus group discussion and key informant interview reveal that river pollution in the city and environmental degradation due to hazardous chemicals exists and increasing through time. Indeed, an economic activity in the city in particular is faster than ever and contributes much environmental goods and bad. The feature of environment and economic growth relation during emerging stage of economic growth, as Kuznets (1955) explain, rising together and calls for effective as well as integrated policy implementation.

\section{ACKNOWLEDGEMENTS}

We are very grateful to the World Resource Institute and informants for their valuable information. Authors appreciate academic partnership of Addis Ababa University (Ethiopia) and Kangwon National University (South Korea). We welcome all potential comments; via, samatouk@gmail.com and hiojung@kangwon.ac.kr.

\section{REFERENCES}

Africa Enterprise Survey. (2011). The African Manufacturing Firm. An analysis based on firm surveys in seven countries in sub-Saharan Africa.

Baldwin, R. E. (1965). Investment Policy in Underdeveloped Countries. Economic Development in Africa. Oxford: Blackwell.

Baldwin, R. E. (2013). The Case against Infant-Industry Tariff Protection. Journal of Political Economy, Vol. 77, No. 3, pp. 295-305.
CRGE. (2011). Ethiopia's Climate-Resilient Green Economy Green economy strategy. FDRE.

Dick, I .(2003).Contemporary Public Administration: The Nigerian Perspective Enugu: John Jacob Classic Publishers.

Ethiopian Environmental Authority-EPA. (1997). Ethiopian Environmental Policy. FDRE.

Ethiopian Science And Technology Commission. (2005). Ethiopian cleaner production center and the United Nations Environmental Program. A briefing note on program for sustainable consumption and production in Akaki River Basin.

Ethiopian Science and Technology Mister. (2008). Ethiopian National Innovation Survey, INV046.

Gebre G, Rooijen DV (2009), Urban Water Pollution and, irrigated vegetable farming in Addis Ababa. Sustainable Development and Multi-sectoral Approaches, $34^{\text {th }}$ WEDC International Conference, Addis Ababa, Ethiopia.

Grubel, H. G.(1966). The Anatomy of Classical and Modern Infant Industry Arguments, Weltwirtschaftliches Archiv, XCVII, 325-42.

Hamilton, A. (1791). A report on manufactures. Presented to the House of Representatives by the Secretary of Treasury. USA.

Hamilton, A. (1791). Report on Manufactures. Reprinted in U.S. Senate Documents, Vol. XXII, No. 172. Washington: Congress.

Ikelegbe, A. (2006). Public Policy Analysis: Concepts, Issues and Cases. Lagos: Imprint Services.

Itanna, F. (1998). Metal concentrations of some vegetables irrigat ed with industrial liquid waste at Akaki, Ethiopia, Ethiopian Journal of Science 96 Vol. 21(No. 1): 133 - 144.

Johnson, C. (1982). MITI and the Japanese Miracle and "Political Institutions and Economic Performance: The GovernmentBusiness Relationship in Japan, South Korea, and Taiwan," in Frederic C. Deyo, ed. The Political Economy of East Asian Industrialism, 136-164.

Kuznets, S. (1955). Economic Growth and Income Inequality. American Economic Review 45(1): 1-28.

Leta, G. (2010). Analysis of Subsurface Contaminant Transport in Akaki Well Field and Surrounding Areas, Central Ethiopia. Global Journal of Researches in Engineering. 14 Vol. 10 Issue 7 (Ver 1.0).

List, F. (1856). National System of Political Economy. Translated by G. A. Matile. Philadelphia: Lippincott.

Meade, J. E. (1955). Trade and Welfare. New York: Oxford Univ. Press.

Mill, J. S. (1909). The Principles of Political Economy. London: Longmans, Green.

Mohamed Ali M. (2002). Industrial pollution and its impact on the little Akaki River, Loughborough University

Nwankwo, B.and Apeh. (2008). Development Administration: Principles and Practice Enugu : Zik Chuks Publishers.

Nweke, E. (2006). Public Policy Analysis: A Strategic Approach. Enugu: John Jacobs Publishers.

Peijun Lia, Xin Wanga, Graeme Allinsonb, Xiaojun Lia, Xianzhe Xionga. (2008). Risk assessment of heavy metals in soil previously irrigated with industrial wastewater in Shenyang, China. Journal of Hazardous Materials 161. 516521. www.elsevier.com/locate/jhazmat/

Rosenstein-Rodan, P. N. (1963). "Notes on the Theory of the 'Big Push,"' in T. Morgan, G. W. Betz, and N. K. Choudry (eds.). Readings in Economic Development. San Francisco: Wadsworth.

Samuel, M. (2005). Investigation of input and distribution of polluting elements in Tinishu Akaki River, Ethiopia, based on the determination by ICP-MS. PhD Thesis. Universiteit Gent. 
Scitovsky, T. (1954). Two Concepts of External Economies, J.P.E., LXII, 145.

Singha,K.P, Mohana, D., Sinhab, S., and Dalwani.R. (2003). Impact assessment of treated/untreated wastewater toxicants discharged by sewage treatment plants on health, agricultural, and environmental quality in the wastewater disposal area. Chemosphere 55 (2004) 227-255. Available online www.elsevier.com/locate/chemosphere/
Van Rooij. B. (2008). Pollution in Industrializing Economies, a Challenge for Regulation. System Design, Compliance, and Enforcement. Leiden University Press.

Wen-hua Liua, Jing-zhu Zhaoa, Zhi-yun Ouyanga, Leif So"derlundb, Guo-hua Liua. (2005). Impacts of sewage irrigation on heavy metal distribution and contamination in Beijing, China. Environment International 31. 805 - 812. 